2017-04

\title{
Social geology integrating sustainability concepts into Earth sciences
}

Stewart, IS

http://hdl.handle.net/10026.1/10862

10.1016/j.pgeola.2017.01.002

Proceedings of the Geologists' Association

Elsevier

All content in PEARL is protected by copyright law. Author manuscripts are made available in accordance with publisher policies. Please cite only the published version using the details provided on the item record or document. In the absence of an open licence (e.g. Creative Commons), permissions for further reuse of content should be sought from the publisher or author. 
Elsevier Editorial System(tm) for

Proceedings of the Geologists' Association

Manuscript Draft

Manuscript Number: PGEOLA-D-16-00092R1

Title: Social Geology - integrating sustainability concepts into Earth sciences

Article Type: Viewpoint

Keywords: geoscience; sustainable development; sustainability; Earth science; geology; society

Corresponding Author: Professor Iain simpson Stewart, PhD

Corresponding Author's Institution: Plymouth University

First Author: Iain simpson Stewart, PhD

Order of Authors: Iain simpson Stewart, PhD

Abstract: Most geologists would argue that geoscientific knowledge, experience, and guidance is critical for addressing many of society's most acute environmental challenges, yet few geologists are directly engaged in current discourses around sustainable development. That is surprising given that several attributes make modern geoscience well placed to make critical contributions to contemporary sustainability thinking. Here, we argue that if geoscientists are to make our know-how relevant to sustainability science, two aspects seem clear. Firstly, the geoscience community needs to substantially broaden its constituency, not only forging interdisciplinary links with other environmental disciplines but also drawing from the human and behavioural sciences. Secondly, the principles and practices of 'sustainability' need to be explicitly integrated into geoscience education, training and continued professional development. 


\section{Detailed Response to Reviewers}

\section{Dear Editor}

Many thanks for the opportunity to revise this manuscript based on the two reviews provided.

As you noted, the review by Mark Maslin was especially constructive, and we have attempted to weave in most of his broader points.

We have also included a specific statement about the extent to which 'sustainability'exists in UK university geoscience departments, although a wider systematic examination of this issue, with real data is beyond the sope of the present article.

We have followed your advice and retained the images, although we acknowledge Maslin's comment that they are not essential to the paper.

There is some restructuring of the argument to reflect the changes made, and a couple of references have been added, including those indicated by Maslin.

Overall we feel that the argument has been sharpened up, though we take heart from the positive endorsements by both referees.

I hope you like the new improved version.

regards,

lain 


\section{Social Geology - integrating sustainability concepts into Earth sciences}

lain S. Stewart,

Sustainable Earth Institute, Plymouth University, Plymouth PI4 8AA, UK. Joel C. Gill,

Geology for Global Development, London, UK.

\section{ABSTRACT}

Most geologists would argue that geoscientific knowledge, experience, and guidance is critical for addressing many of society's most acute environmental challenges, yet few geologists are directly engaged in current discourses around sustainable development. That is surprising given that several attributes make modern geoscience well placed to make critical contributions to contemporary sustainability thinking. Here, we argue that if geoscientists are to make our know-how relevant to sustainability science, two aspects seem clear. Firstly, the geoscience community needs to substantially broaden its constituency, not only forging interdisciplinary links with other environmental disciplines but also drawing from the human and behavioural sciences. Secondly, the principles and practices of 'sustainability' need to be explicitly integrated into geoscience education, training and continued professional development.

\section{Introduction}

The study of the Earth, its history and how it works provides essential knowledge, experience, and guidance on how to meet many of society's most acute planetary challenges (UNESCO 1998, American Geosciences Institute 2011, The Geological Society of London 2014). Through global socio-economic drivers of international trade, industrialisation, urbanisation and coastalisation we are using more and more natural resources, and the way we are utilising our resources has started to affect our ecosystem more noticeably and irreversibly than ever before. All this has the potential to impact our ability to sustain the economy, protect national security, eradicate global poverty and preserve the natural environment. Although this interface between wise management of geological resources and risks and social development has been called 'social geology' (Mata-Perello et al. (2012), it 
has been argued (Mora 2013) that '...most geologists tend not to be involved in discussions around sustainable development' (Fig 1).

The apparent disconnect between geoscience and sustainability may be because the United Nation's (2015) Sustainable Development Goals (SDGs) do not appear, at first glance, to be overtly geological (Fig 2). And yet, not only is geoscience important to many of the SDGs (Gill, 2016a) but underpinning the whole notion of the sustainability agenda is the broad acceptance that humans are now a dominant geological force on the planet, warranting our own bespoke epoch: the Anthropocene (e.g. Steffen et al., 2011, Waters et al. 2016) (Fig 3). The fact that some of the cumulative impacts of our anthropogenic changes are now becoming significant enough to be able to be compared with similar events in the geological past means that, more than ever before, many of the central tenets of Earth science bear directly on humanity. In this burgeoning 'human age' the applied aspects of economic geology, petroleum geology, engineering geology, hydrogeology, geohazards and the use of the land-surface for agriculture, housing and infrastructure assume even greater importance, alongside the geological facets of climate science, land and environmental management, and disaster risk reduction. In practice, however, it would seem that most geologists have yet to grasp the wider societal interests and implications of the Anthropocene Epoch debate (see Lewis \& Maslin 2015, Ellis et al. 2016).

Making sustainability thinking more central to geology is not a new idea. Over two centuries ago, James Hutton's seminal 'Theory of the Earth' placed what he referred to as the 'physiology' of our planet at the heart of geology, with his 1788 opus opening with the remark: 'This globe of the earth is a habitable world, and on its fitness for this purpose, our sense of wisdom in its formation must depend'. Given that modern geology rests on such a Comment [J1]: ditto foundation, it is perhaps surprising that today the geoscience community is less fully represented in in current discourses on Earth's health and well-being in comparison with other scientific disciplines (Mora 2013).

Our under-representation is particularly surprising given that several attributes make modern geoscience well placed to make critical contributions to contemporary sustainability issues. As 'Earth System Science', it grapples with the complex linkages between the atmosphere, hydrosphere, cryosphere, biosphere, and lithosphere, giving a unique wholeplanet perspective. Those inter-linkages have ensured that Earth has maintained itself as a sustainable system over billions of years, recycling the vital components for a habitable 
planet. Geologists, therefore, possess a valuable synoptic and temporal conceptual framework for evaluating Earth's sustained viability for life.

Even as the rise of Earth System Science has shifted the frontline of our curiosity-driven discipline toward solution-oriented science (Schlosser \& Pfirman 2012), conventional geological inquiry still remains critical. Many of the long-standing methodological limitations of Earth science - incompleteness of data, lack of experimental control, changes occurring too gradually for direct observation or measurement - pertain equally to sustainability science. And with geologists trained in a range of specialised problem-solving skills, they would seem especially well suited to the challenges of developing more sustainable environmental practices. Indeed, as Gosselin et al. (2013) contend:

'As a historical and interpretative science, geology can inform society about interactions in coupled human-environmental systems because our skills and proficiencies allow us to recognize the varying manifestations of phenomena at different spatial and temporal scales.'

So, how can the geoscience community increase its involvement and profile in the sustainable development arena? The science behind sustainability started out as the study of the interactions between human and environmental systems, but it has now evolved into a diverse applied science that seeks societal action to preserve the natural environment through the use and application of scientific knowledge (Bettencourt \& Kaurc 2011). Reflecting this current perspective, if geoscientists are to make our Huttonian 'wisdom' relevant to sustainability science, two aspects seem clear. Firstly, our geoscience community needs to substantially broaden its experience. And secondly, we need to explicitly integrate 'sustainability' into geoscience education, training and continued professional development.

\section{Broadening our geoscience experience}

With regard to the first concern, it is generally accepted that the 'science strategy to meet the challenge of finding the resources to meet increasing demands and to predict and, if possible, mitigate the adverse impacts that we are having on our planet has to be broad and multidisciplinary.' (Geological Survey of India 2011). According to the Geological Survey of India's 'Geoscience for Sustainable Development' report, this strategy will require 
geologists, geochemists, geophysicists, geomorphologists and the like to work together in integrated projects with engineers and planners. In reality, however, we contend that the interchange will need to be more ambitious than this. If we are to usefully confront societal threats to an ecologically viable planet, the geoscience community will need to collaborate with allied Earth science disciplines such as biology, zoology, ecology, physical geography, agronomy and environmental science.

The importance of working in collaboration with other disciplines to promote sustainability, can be seen in examples from the water sector. Constructing sustainable water supplies in regions such as rural Asia and Africa requires more than an understanding of the technical geoscience and hydrogeology required to identify, extract and monitor groundwater. Sustainability requires an appreciation of location-specific social, cultural, economic, ethical, and environmental factors (Amadei, 2004), ensuring the project has maximum, positive impact and is characterised by ethical interactions with society (Fig 4). The literature is rich in examples of water projects that have failed, despite a sound technical grasp of the underlying geology, due to poor engagement of communities and an inability to strengthen their capacity to maintain and manage the water supply (Elmendorf and Isely, 1981; Carter and Bevan, 2008). In contrast, sustainable water projects are characterised by strong user participation at each stage (including the geophysical survey, pumping test, water quality assessment) and effective project supervision (Narayan, 1995; Adekile, 2014). In this context, sustainability is achieved either through individuals combining professional competency in hydrogeology, engineering, social sciences and community development, or through effective collaborative teams, drawing from these and other disciplines.

Addressing real-world concerns such as access to clean water (Fig 5) highlights how, in order to adequately resolve the complexity of contemporary human-environment conflicts, geoscientists will need to draw from the social sciences. The human and behavioural sciences in particular - human geography, anthropology, psychology and sociology - offer robust, empirically-based perspectives on how individuals and communities face up to geoenvironmental challenges, and on how scientists can deal with the public over socially contested geoscientific issues (Rapley \& De Meyer 2014, Stewart 2016). Such perspectives also show that to be relevant in the public arena, geoscientists are going to have to rethink the manner in which they operate, with Schlosser \& Pfirman (2012, p.588) recommending that: 
'...to work on practical problems, Earth scientists will have to take on the role as participants in a broader team of researchers, rather than as observers or advisors, as is currently more familiar. Collaboration with the social sciences, humanities and stakeholders will be at the centre of successful ways forward. Direct involvement of the public through crowd-sourcing, as well as conflict resolution between multiple stakeholders - academic, business, community and government — can help build the two-way communication that is necessary for progress.'

The issue of effective communication is especially critical in ensuring that geoscientific know-how reaches those who most need it, whether that be policy makers, civic authorities, business leaders, the media or the public at large. Those areas of geoscience that are at the frontline of societal engagement - most acutely in the fields of climate change and natural hazards - appreciate all too readily that simply explaining the science rarely motivates meaningful mitigation among those at risk (e.g. Wachinger et al. 2013, Rapley \& De Meyer 2014). For decades, social scientists have recognised this dilemma and have developed methodologies and strategies for deconvolving public attitudes, motivations and perceptions about scientific and technological issues (Fig 6) (for a review, see National Academies of Sciences, Engineering, and Medicine. 2016). The crux of the problem is that, as one recent attitudinal survey concludes, '... public concerns about contentious science or technologies are almost never about the science - and scientific information therefore does little to influence these concerns.' (Cormick 2014). If geoscientists are going to be effective contributors to sustainability issues then we are going to have to learn to better communicate what we know and why it is important.

Geology's communication problem arises in part because ordinary people afford little attention to or interest in to the geological realm (Stewart \& Nield 2013). Few have anything but a vague and often misconceived sense of the subsurface, an alien environment which lies hidden and out of bounds (Gibson et al 2016). Moreover, most struggle to grasp the cumulative impact of slow, gradual changes over periods that exceed human timespans, or appreciate the feedbacks and tipping points lurking within complex natural systems. That unfamiliarity with geoscience is understandable given that most countries lack a direct exposure to geology within the school curriculum and an absence of popular Earth science in the mass media (Stewart \& Nield 2013). Both deficiencies, to some extent, reflect a lack of incentive among academics and industry professionals to 'go public' with 
their science. Recently, however, this long-standing science-public disconnect is being countered as national governments, funding agencies and institutions demand greater public accountability for research through increased outreach activity. More and more, geoscientists are being expected not just to undertake geological investigations but to justify why their work is important and tell end users what it means for them. In that context, the impetus to convey geological relevance to sustainable development will only increase.

With these growing societal demands comes an increasing public scrutiny of the ethical dimensions of our geoscientific practices (Wyss \& Peppoloni, 2015). Organisations such as the International Association for Promoting Geoethics are working through 21 national chapters to demonstrate the importance of all geoscientists having an awareness and understanding of the ethical, social and cultural implications of Earth sciences education, research and practice (IAPG, 2016). That is because, increasingly, society will look to the geosciences not only for sustainably providing its resource base (Lambert 2001) but also resolving the impact of developmental projects on the environment, human health and the severity of natural hazards (Fig 8). The emerging view is that '...geoscientists' professional duties go beyond scientific and technological knowledge and skills. Ethics is part of their (our) professional responsibility. (Martinez-Frias et al., 2011, p.257).

\section{3. integrating sustainability into geoscience education}

Despite these challenges, it seems clear that geology and geologists can have a significant role in sustainability science, and specifically in delivering the Sustainable Development Goals (Fig. 7). To achieve this, however, sustainable geoscience will need to become integrated into geological education and professional development. A comprehensive evaluation of the extent to which sustainable thinking is embedded within geoscience teaching worldwide is beyond the scope of this article, but clearly there are markedly different educational practices. In the USA, for example, scientists looking at environmental change, climate change and sustainability tend to be housed in broad Earth and Environmental Science departments. Moreover, 'sustainability is often promoted as a strong organizing principle for modern liberal arts and technical education programs, requiring systems thinking, synthesis, and contributions from all disciplines - geoscientists, natural/ physical scientists, social scientists, human and behavioural scientists, and engineers' (Gosselin et al. 2013). By contrast, a cursory analysis of the undergraduate curricula of the 
twenty highest rated UK Earth science departments (University Subject Tables 2017 1) reveals only one course with Sustainability' in a module title and only two that refer explicitly to sustainability or sustainable development in their module descriptions. The UK geoscience community, it would appear, is more reluctant than its North American counterpart to embrace sustainability in its training.

Addressing this deficiency could take various forms. An introductory undergraduate module on 'Geology and Society' is a simple and obvious first step in highlighting geological relevancy in the broad arena of sustainable development; in many Geography Departments in the UK, a cluster of courses address these requirements by bringing together Physical, Social and Cultural Geographers. At a more advanced level, existing undergraduate courses on industry-related topics such as economic geology, petroleum geology, engineering geology and applied physical geography could readily be reframed from a sustainability angle. Such reframing might incorporate emerging issues in the energy, resource and construction sectors around social license to operate and corporate sustainable responsibility, regulatory and legal aspects of the subsurface realm, as well as new economic evaluations of 'natural capital' and environmental impacts. A fundamental element, however, will be to prepare geoscientists for their evolving future role in the coming age of clean energy, resource constraints and smart cities. In this context, the most substantive way to integrate sustainability concepts into Earth science training will be to design and develop fresh postgraduate courses that exploit interdisciplinary alliances within universities to establish more holistic Earth science perspectives to pressing societal concerns.

Whatever shape 'social geology' may take, the university setting provides an essential framework to bring together students from diverse disciplines with a shared interest in disparate aspects of sustainable development. An instructive example is disaster risk reduction, which can be delivered in modules to geoscientists, engineers, architects, health professionals, social scientists and others. Integrating students from these disciplinary divisions at an early stage of their training and career would help to nurture an appreciation of collaborative research, complementary topical knowledge and different research methodologies, and the skills required to communicate across disciplinary divides. A more prominent framing of sustainability concepts within formal geoscience education programmes

\footnotetext{
${ }^{1} \mathrm{http} / /$ www.thecompleteuniversityguide.co.uk/league-tables/rankings?s=geology
} 
and continued professional development programmes will help to ensure that it becomes a mainstream goal and not simply a specialist sideshow.

Embedding sustainability thinking into undergraduate and postgraduate geoscience courses can be supported by extracurricular activities exposing students to new ideas, research skills, and career paths. In the UK, Geology for Global Development (GfGD) is a not-for-profit organisation working to mobilise and equip geoscientists to engage in sustainable development. GfGD works to support geoscientists from the start of their careers to consider the skills and understanding required to support an effective, sustainable application of their geoscience. Examples of key supporting skills include: cultural understanding, cross-disciplinary communication, diplomacy, community mobilisation, knowledge exchange, social science research techniques, and analysis of historical records (Gill, 2016b). GfGD supports geoscientists to develop these skills and areas of complementary understanding through a network of student-led university groups, conferences, placements, and engagement in education, outreach and development activities. Together with an enhanced understanding of social vulnerability, development theory and global frameworks such as the Sustainable Development Goals, these skills can aid geoscientists in gathering, understanding and integrating knowledge about location-specific social, cultural, economic and environmental dynamics, to improve their engagement in sustainable development.

\section{Conclusion}

Building sustainability into geoscience curricula and professional development training seems critical for the emergence of a new generation of geo-professionals well-versed in understanding and addressing sustainability issues (Mora 2013). How it will be done is uncertain, and more guidance on how geologists might consider the social consequences of their discipline could come from national geological societies and international geoscientific unions, and arguably even bodies such as the Royal Society or National Academy of Sciences. Certainly there are broader benefits to ensuring it is done. Teaching geology students to work with other scientists, politicians, business professionals, social entrepreneurs, and practitioners in charities and non-governmental organisations to develop viable solutions to current and future environmental and resource challenges is likely to significantly increase their employability prospects. Moreover, stronger academic engagement with local environmental issues will draw in external community-based stake- 
holders, including employers. In turn, such novel engagements may forge a more sustainable curriculum:

The inclusion of these modules or exercises in introductory courses could also have the effect of making geology more relevant to students who are fascinated by the subject but who do not pursue it, possibly because they see it as less salient, prestigious, or scientific than other disciplines ..., particularly by minority students who may view geology simply as the study of rocks.... (Mora 2013, p.37).

Professional geologists, whether in academia or in industry, are only too aware that their venerable discipline is more than 'rocks'. Demonstrating our relevance to sustainable development through the application of social geology will be an important way of proving it.

\section{ACKNOWLEDGEMENTS}

The authors thank Mark Maslin and an anonymous referee for constructive reviews that helped hone our arguments and also Jim Rose for encouraging the submission of this article. 


\section{REFERENCES}

Adekile, D., 2014, Supervising Water Well Drilling-A Guide for Supervisors (revised edition): St. Gallen, Switzerland, Rural Water Supply Network, 24 p.

American Geosciences Institute 2011. Critical Needs for the Twenty-first Century: The Role of the Geosciences.

Bettencourt, L.M.A., and Kaurc, J., 2011, Evolution and structure of sustainability science: Proceedings of the National Academy of Sciences, 108, 19,540-19,545.

Carter, R.C., and Bevan, J.E., 2008, Groundwater development for poverty alleviation in sub-Saharan Africa, in Adelana, S., and MacDonald, A., eds., 2008, Applied Groundwater Studies in Africa: International Association of Hydrogeologists Selected Papers in Hydrogeology 13, 25-42.

Cormick, C. 2014. Community Attitudes Towards Science and Technology in Australia. CSIRO, 26p.

Ellis, E., Maslin, M., Boivin, N.L. and Bauer, A., 2016. Involve social scientists in defining the Anthropocene. Nature, 540(7632), 192-193.

Elmendorf, M., and Isely, R., 1981, The Role of Women as Participants and Beneficiaries in Water Supply and Sanitation Programs: Water and Sanitation for Health Project (USAID) Report 11, 1-28.

Geological Society of London 2014. Geology for Society. The Geological Society of London www.geolsoc.org.uk/geology-for-society (accessed 9 April 2016).

Gibson, H., Stewart, I.S., Pahl, S. and Stokes, A., 2016. A" mental models" approach to the communication of subsurface hydrology and hazards. Hydrology \& Earth System Sciences, 20(5), 1737-1749.

Gill, J.C., 2016a, in press. Geology and the Sustainable Development Goals. Episodes.

Gill, J.C., 2016b, Building good foundations: Skills for effective engagement in international development, in Wessel, G.R., and Greenberg, J.K., eds., Geoscience for the Public 
Good and Global Development: Toward a Sustainable Future: Geological Society of America Special Paper 520, p. 1-8.

Gosselin, D., Manduca, C., Bralower, T., Mogk, D. 2013. Transforming the Teaching of Geoscience and Sustainability. Eos, 94, 221-222.

IAPG. 2016. International Association for Promoting Geoethics. Available online: http://www.geoethics.org/ (accessed 9 April 2016).

Lambert, I.B. 2001. Mining and sustainable development: considerations for minerals supply. Natural Resources Forum, 25, No. 4, 275-284.

Lewis, S.L. and Maslin, M.A., 2015. Defining the Anthropocene. Nature, 519(7542), 171180.

Martínez-Frías, J., González, J.L. and Pérez, F.R., 2011. Geoethics and deontology: from fundamentals to applications in planetary protection. Episodes, 34(4), 257-262.

Mata-Perelló, J.M., Mata-Lleonart, R., Vintró-Sánchez, C. \& Restrepo-Martínez, C. 2012. Social Geology: A New Perspective On Geology. Dyna, 79, 171, 158-166,

Mora, G., 2013. The need for geologists in sustainable development. GSA Today, 23(12), 33-37.

Narayan, D., 1995, Contribution of People's Participation: Evidence from 121 Rural Water Supply Projects: World Bank Environmentally Sustainable Development Occasional Paper $1,122 \mathrm{p}$.

National Academies of Sciences, Engineering, and Medicine. 2016. Communicating Science Effectively: A Research Agenda. Washington, DC: The National Academies Press. doi: $10.17226 / 23674$.

Rapley, C. and De Meyer, K., 2014. Climate science reconsidered. Nature Climate Change, 4(9), 745-746.

Schlosser, P. and Pfirman, S., 2012. Earth science for sustainability. Nature Geoscience, 5(9), 587-588. 
Steffen, W., Grinevald, J., Crutzen, P., \& McNeill, J. (2011). The Anthropocene: conceptual and historical perspectives. Philosophical Transactions of the Royal Society of London A: Mathematical, Physical and Engineering Sciences, 369(1938), 842-867.

Stewart, I.S. \& Nield, T. 2013. Earth stories: context and narrative in the communication of popular geoscience. Proceedings of the Geologists' Association, 124, 699-712.

Stewart, I.S. 2016. Sustainable Geoscience. Nature Geoscience, 9 (April), 262.

Tingay, M.R.P., Rudolph, M.L., Manga, M., Davies, R.J. and Wang, C.Y., 2015. Initiation of the Lusi mudflow disaster. Nature Geoscience, 8(7), 493-494.

Waters, C.N., Zalasiewicz, J., Summerhayes, C., Barnosky, A.D., Poirier, C., Gałuszka, A., Cearreta, A., Edgeworth, M., Ellis, E.C., Ellis, M. and Jeandel, C., 2016. The Anthropocene is functionally and stratigraphically distinct from the Holocene. Science, 351(6269), p.aad2622.

United Nations, 2015, Sustainable Development Goals (Online). Available at: http://www.un.org/sustainabledevelopment/sustainable-development-goals/ (accessed 3 January 2017).

UNESCO, 1998. Environmental and Engineering Geology for Sustainable Development, Moscow University of Engineering Ecology, Moscow, p.201.

Wachinger, G., Renn, O., Begg, C. and Kuhlicke, C., 2013. The risk perception paradoximplications for governance and communication of natural hazards. Risk analysis, 33(6), 1049-1065.

Wyss, M. \& Peppoloni, S. (Editors) 2015. Geoethics. Elsevier. 


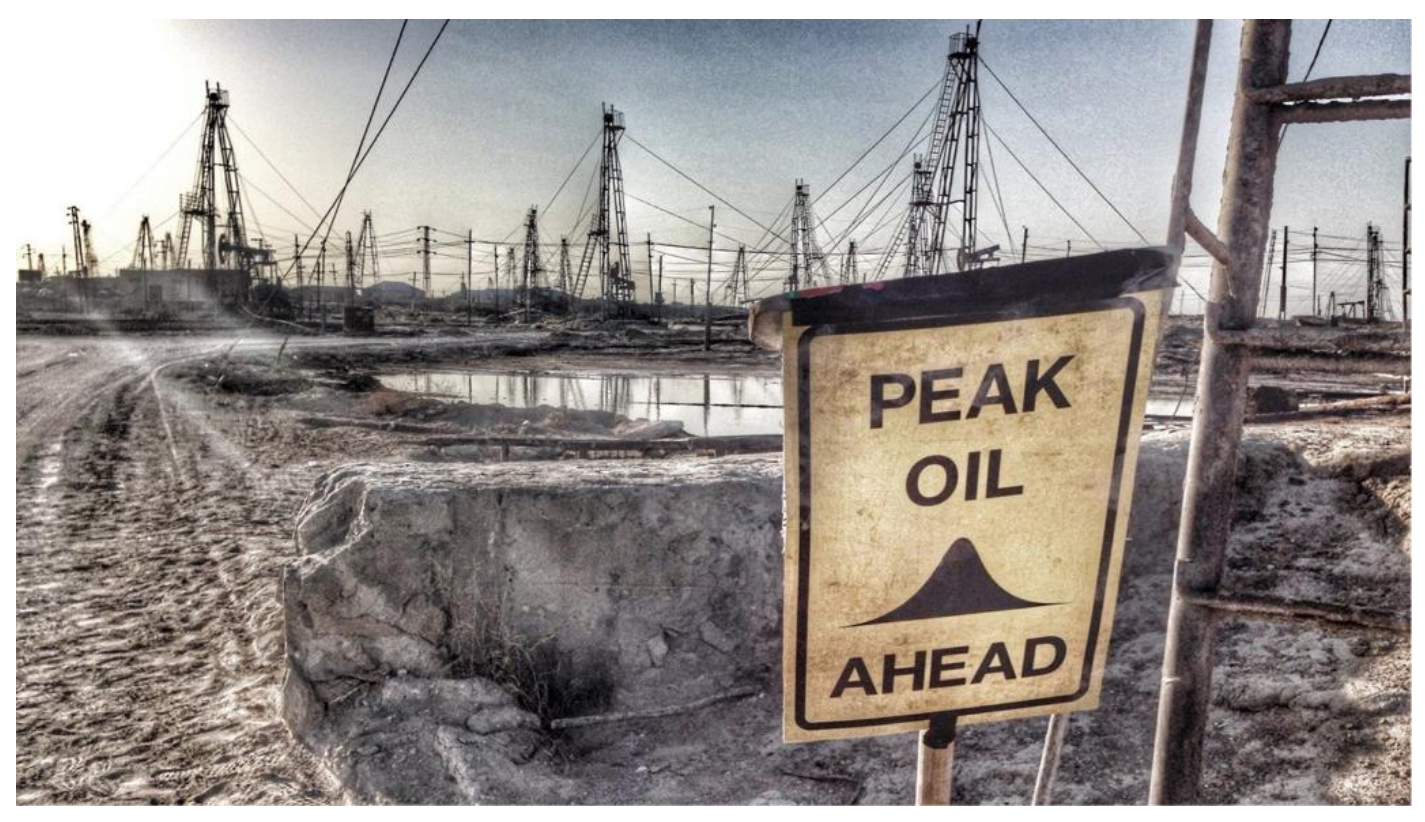

Fig.1. How we exploit our raw materials and natural resources has significant impacts on the future health and well-being of our economy, our environment and ourselves. Although most aspects of securing a sustainable future - such as meeting Society's rising energy demands - have strong geological underpinning, geologists rarely find themselves central to sustainable development thinking. 


\section{SUSTAINABLE DEVELOPMENT

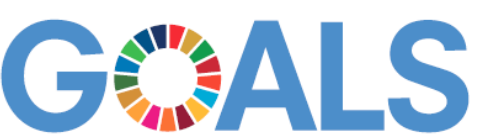

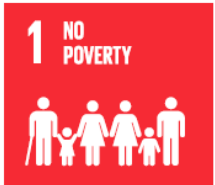
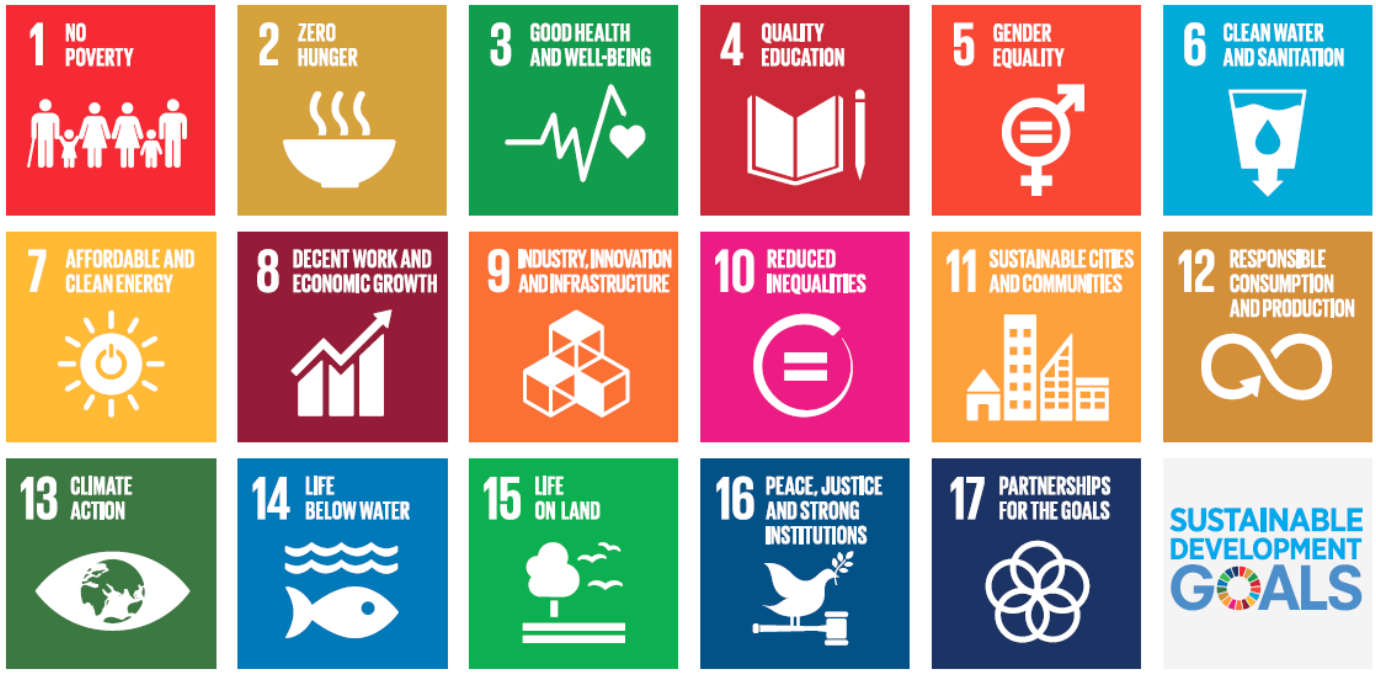

SUSTAINABLE DEVELOPMENT G\%ALS

Fig 2. The UN Sustainable Development Goals (United Nations 2015). The apparent disconnect between geoscience and sustainability may be due to the fact that the SDGs do not appear to be overtly geological. 


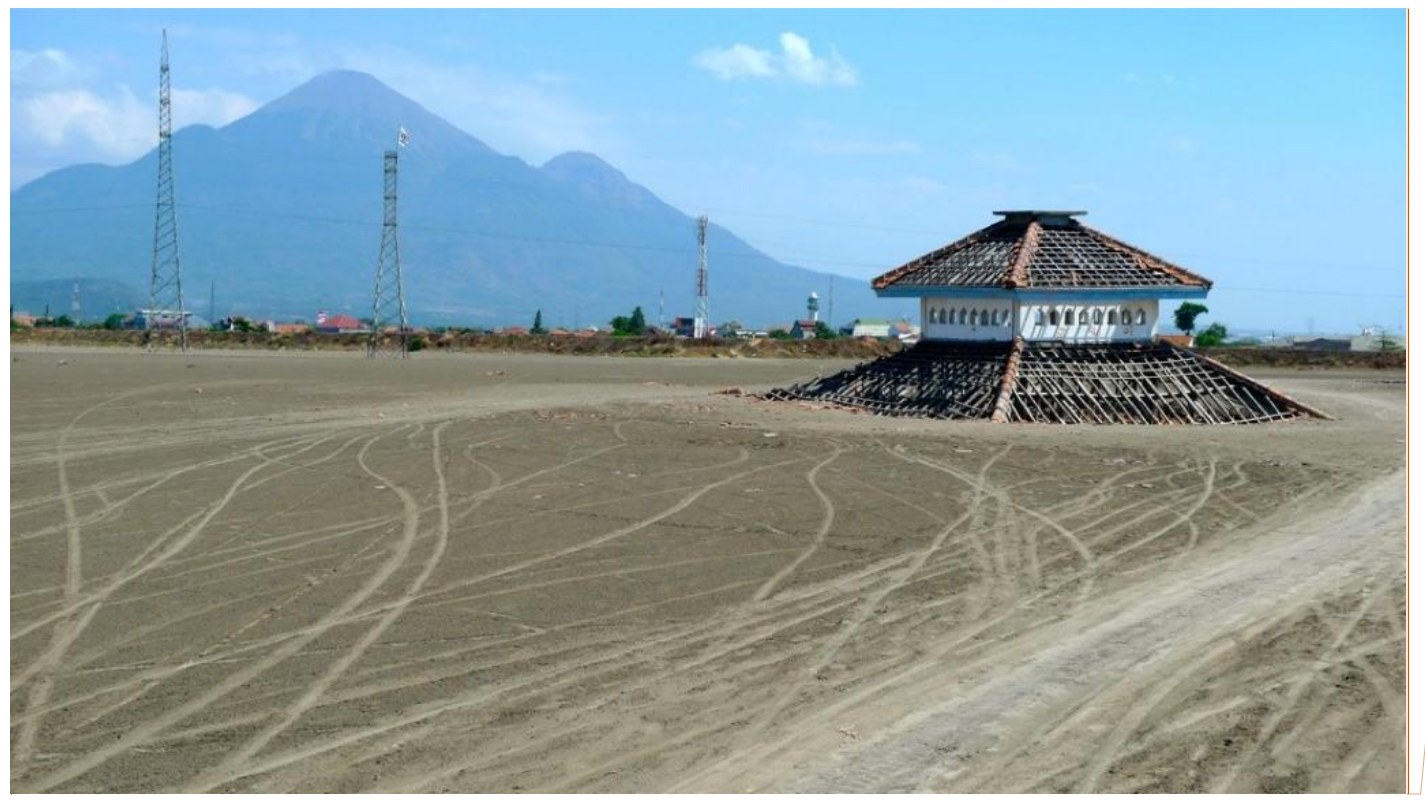

Comment [GJC4]: Not referred to in

the text anymore (i.e., no Fig 3)

Fig.3 The 2006 LUSI mud volcano outburst in eastern Java, Indonesia, provides an example of how human actions can be a major agent of environmental change on the planet. Local drilling for natural gas is widely considered to have triggered the outburst, which after a decade of continuous leakage has displaced 40,000 people and cost almost US $\$ 3$ billion in damages (Tingay et al. 2015). 

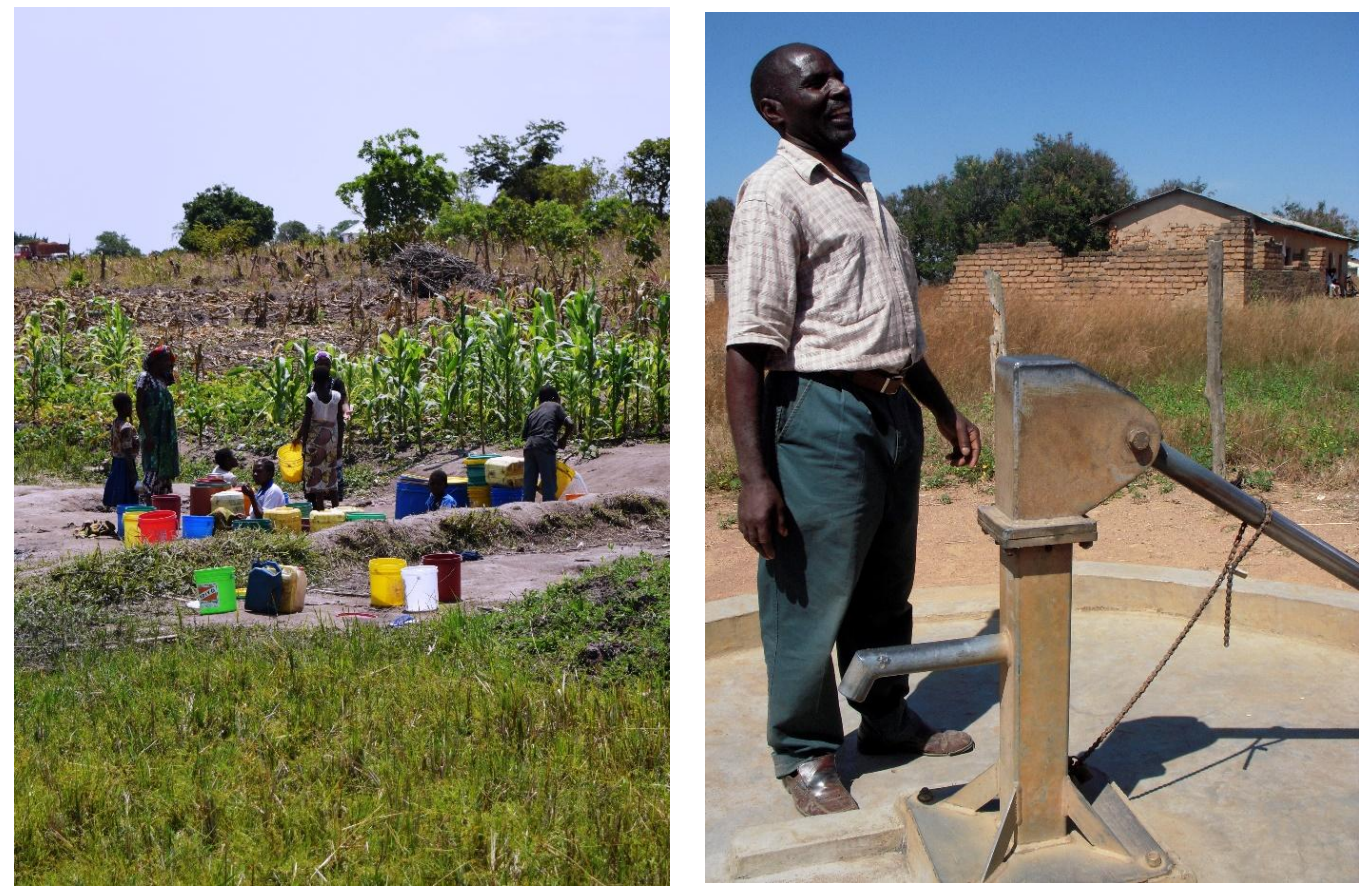

Fig. 4. Contrasting water projects in Tanzania, showing (left) women collecting water from holes in the ground due to their shallow well not working in the 2014 dry season (constructed in 2013/4), and (right) a fully functioning (as of 2009) 30-year old borehole with a dedicated caretaker. 


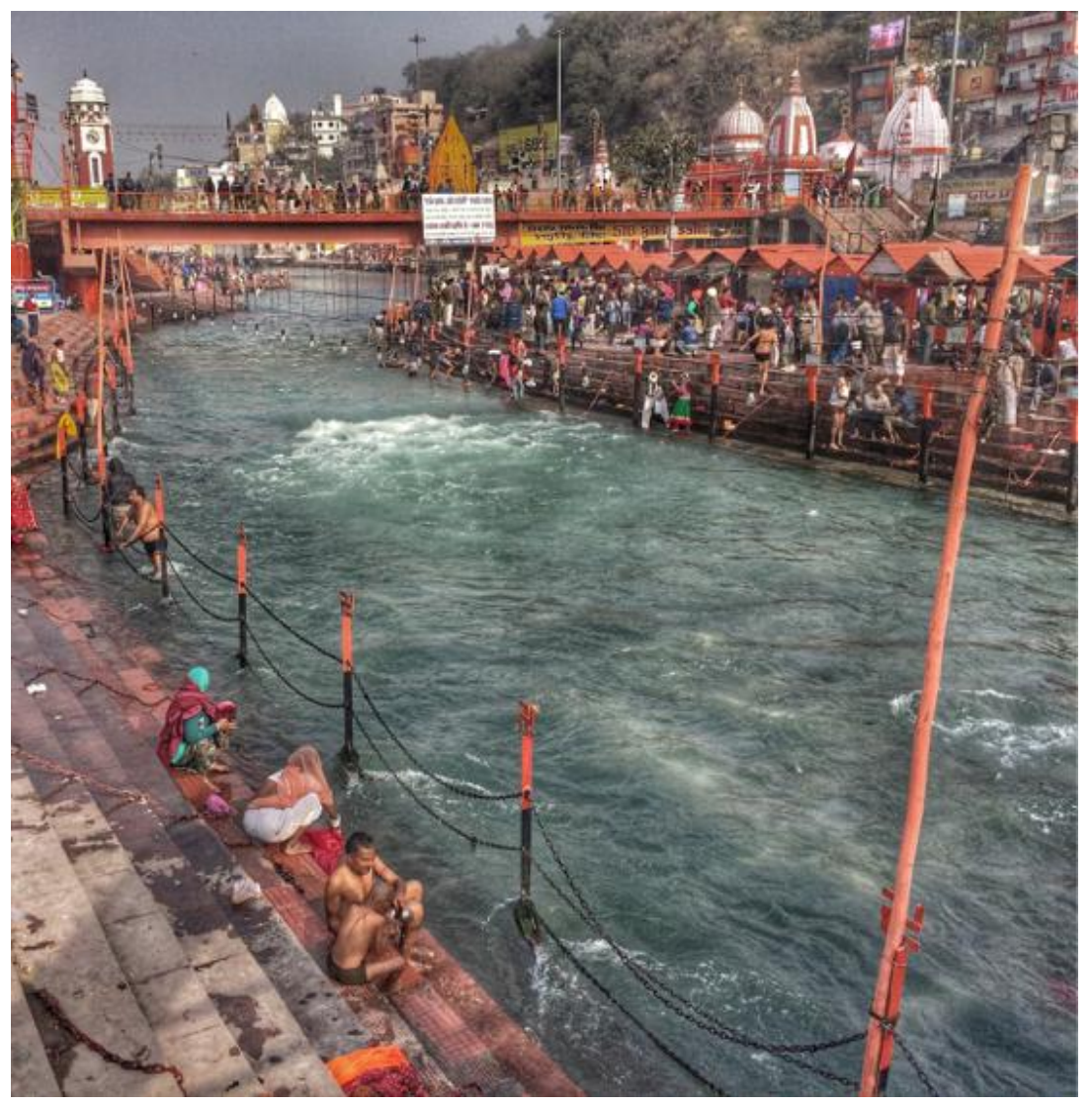

Fig. 5. Ritual bathing in the Ganges river at the important Hindu pilgrimage site of Haridwar, Uttarakhand, India. If geoscientists are to usefully contribute to addressing acute societal threats, such as reducing the risk of river flooding or maintaining access to clear water, then they will need to work not only with scientists in allied environmental research fields but also with those in more remote disciplines to appreciate the social, political and cultural context of the problem. 


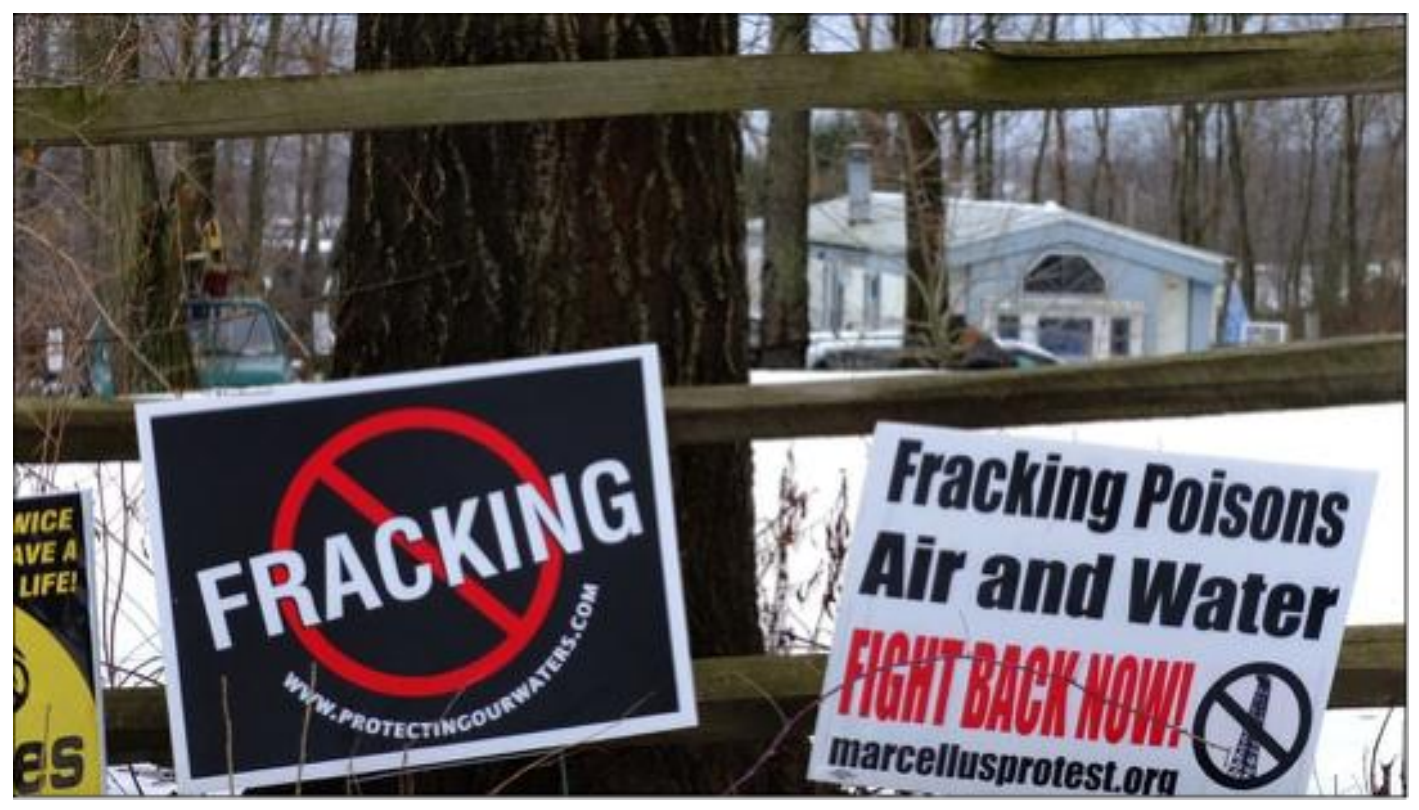

Fig.6 Geoscientific concerns quickly get subsumed into and lost within wider social, economic, and political concerns. Studies from the social sciences show that simply explaining the technical aspects of controversial geoscience interventions, such as hydraulic fracturing ('fracking'), rarely effects meaningful attitudinal change among those individuals and communities at risk. Specifically, public concerns about contentious science are almost never about the science - and scientific information therefore does little to influence these concerns. 


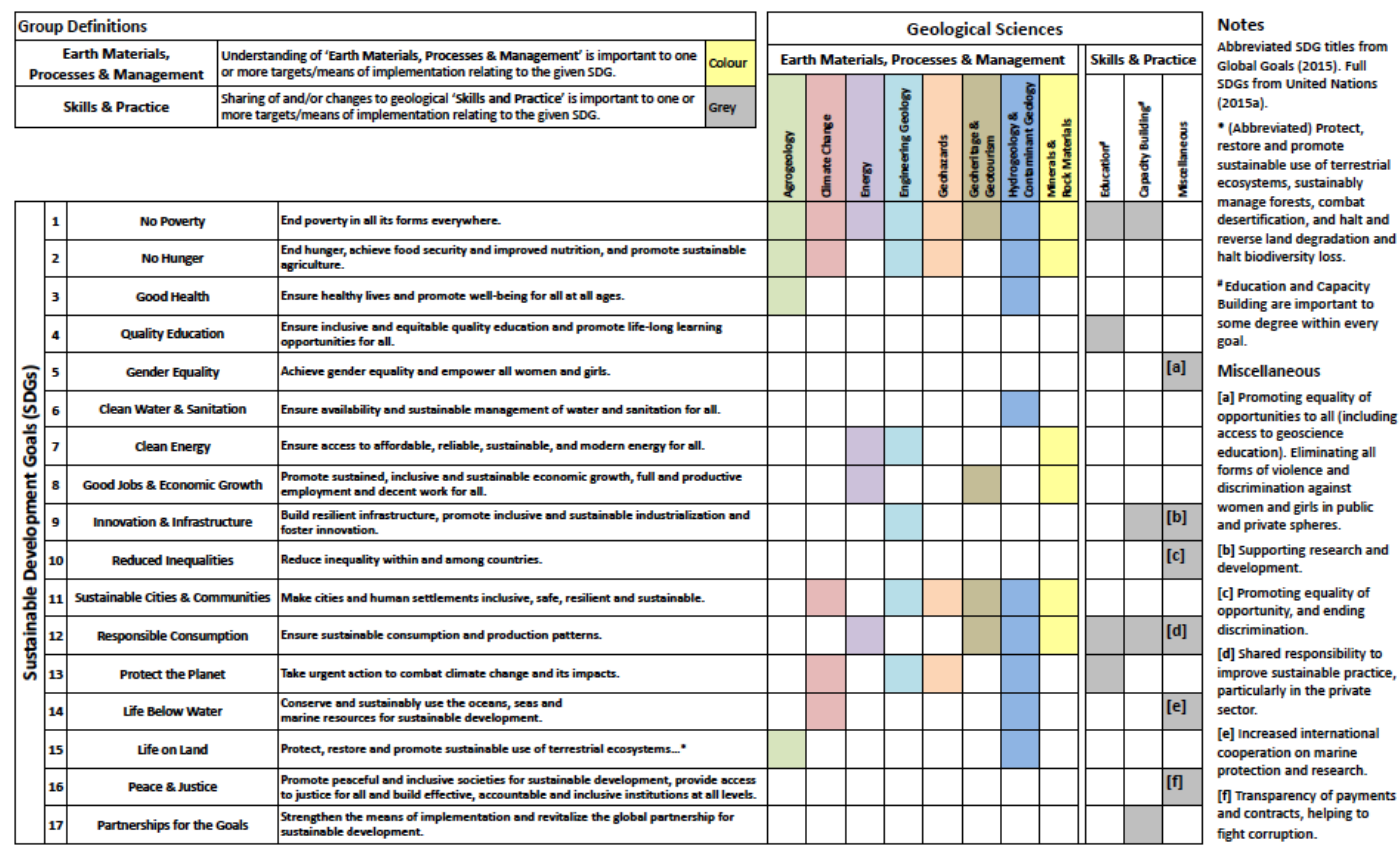

Fig 7. Geology and the Sustainable Development Goals: A matrix to visualise the role of geologists in helping to achieve the internationally-agreed Sustainable Development Goals. (adapted from Gill 2016a) 


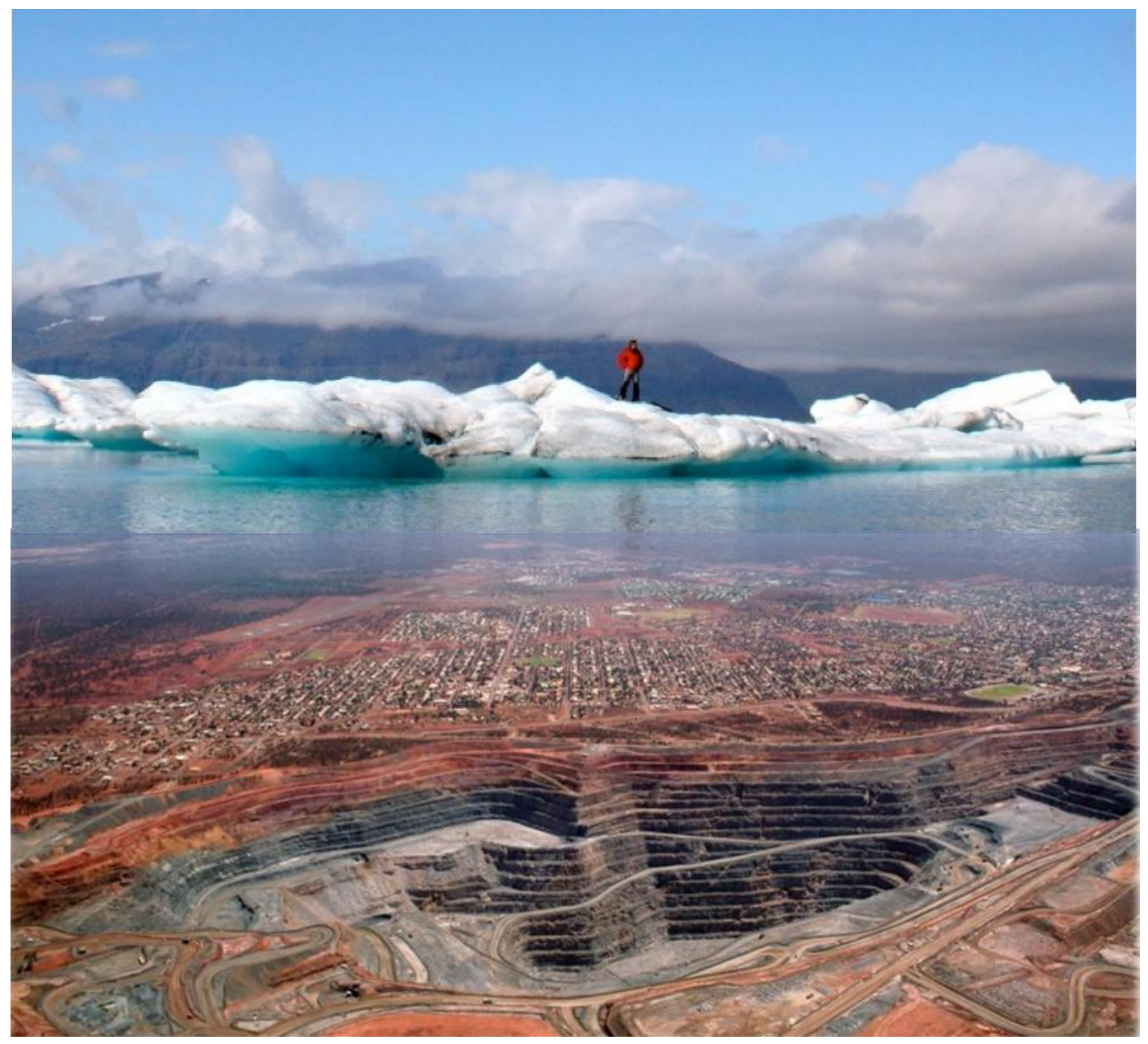

Fig.8. Society looks to the geosciences not only for sustainably providing the resource base for the global economy, but also resolving the impact of developmental projects on the environment, the severity of natural hazards, and human health. Balancing the opposing demands of 'exploitation' and 'stewardship' will be central to the ethical dimensions of geoscience in the $21^{\text {st }}$ century. 